\title{
When practice belies 'theory': Form, function and frequency of if-conditionals in specialised discourse
}

\section{Elizabeth Rowley-Jolivet and Shirley Carter-Thomas}

\section{(2) OpenEdition \\ Journals}

Electronic version

URL: http://journals.openedition.org/asp/343

DOI: $10.4000 /$ asp. 343

ISBN: 978-2-8218-0406-7

ISSN: 2108-6354

\section{Publisher}

Groupe d'étude et de recherche en anglais de spécialité

\section{Printed version}

Date of publication: 1 November 2008

Number of pages: 39-61

ISSN: 1246-8185

\section{Electronic reference}

Elizabeth Rowley-Jolivet and Shirley Carter-Thomas, « When practice belies 'theory': Form, function and frequency of if-conditionals in specialised discourse », ASp [Online], 53-54 | 2008, Online since 01 November 2011, connection on 30 April 2019. URL : http://journals.openedition.org/asp/343 ; DOI 10.4000/asp.343

This text was automatically generated on 30 April 2019.

Tous droits réservés 


\title{
When practice belies 'theory': Form, function and frequency of if- conditionals in specialised discourse
}

\author{
Elizabeth Rowley-Jolivet and Shirley Carter-Thomas
}

\section{Introduction}

1 In recent years, corpus-based and corpus-driven grammars and language studies (e.g., Collins COBUILD 2005; Biber et al. 1999; Hunston 2000) have revealed that language in use often differs significantly from traditional linguistic analyses based on structural units and grammarians' intuitions of language features. Language users constantly make choices in the grammar and lexicon depending on various contextual factors such as the communicative aim and setting, the mode (speech vs. writing), the genre, etc., and these variations have been shown to exhibit systematic patterns. A corpus approach to grammar is particularly relevant to English for Specific Purposes which ever since the outset (Barber 1962) has focused on the selective use that disciplinary communities make of the common language in response to their specific epistemic and communicative needs. The process of selection applies not only to the lexis or specialised terminology of the disciplines, but also to the different ways core syntactic constructions are exploited in specialised discourse.

Differences that characterise a specialised use of syntax can be of three kinds: differences in frequency, differences in function, and differences in formal features. Frequency information about grammatical patterns is perhaps the most well-researched aspect in ESP. Certain syntactic constructions are used with a much higher or lower frequency than in general usage. A classic example here would be the much greater use of passives and nominalisations in research articles than in conversation or literature. Less obvious, but equally important, are differences in the functions that a particular syntactic construction may fulfil in specialised discourse. Many common syntactic constructions have multiple functions; it is therefore necessary to see which functions are relevant and 
which are irrelevant in the specialised discourse at issue. The construction selected for the present study, the if-conditional, is a case in point, as this construction is characterised by a great functional versatility (Dancygier 1998: 2). Lastly, syntactic patterns often have several formal variants which are not interchangeable as these subtle distinctions in form are closely linked to semantic nuances. One aim of the study will be to look at which particular formal features of the if-construction are prevalent and why.

the differences encountered in specialised syntax use can be attributed to the discipline and others to the genre. During the process of linguistic socialisation into these specialised discourses, both non-native English and novice researchers, if they want to be rhetorically effective, need to master these linguistic and discursive specificities and conventions of their discipline and its associated discourse genres. However, their previous exposure to or training in English does not necessarily prepare them adequately for this - and on occasion may even prove to be negative training that they have to 'unlearn' in order to become professionally proficient.

4 To investigate the nature and extent of this potential discrepancy between theory and practice, we have chosen to restrict ourselves to one scientific discipline, namely oncology, a branch of medicine. We will focus on differences between two medical genres: research articles (RA) and conference presentations (CP) within this one discipline, in relation to the use of a single syntactic construction, if-conditionals. We have selected this particular construction because if-conditionals can be a highly valuable resource in scientific discourse. Their inherent non-assertiveness or 'iffiness' (Carter-Thomas 2007) means that they can be used for hypothesizing and hedging. In domains such as medicine where absolute certainty is frequently impossible they therefore enable researchers to retain a certain distance from their claims (Salager-Meyer 1994; Adams-Smith 1984; Prince et al. 1982). This is particularly true of the clinical investigations analysed here where reasoning is inductive and evidence must be carefully weighed. If-conditionals can also have an important argumentative role, enabling the text producer to set up an alternative argumentative or fictional space to promote research claims, by envisaging alternatives and conceding competing points of view. At the same time results obtained in science, and in medical research in particular, are often established under strictly controlled conditions. Researchers need to carefully delimit the research space and specify the conditions under which the research was carried out. Conditional constructions can play an extremely important role here, in specifying for example the eligibility criteria for patients involved in trials.

\section{Literature on Conditionals}

Our aim in the present study is to investigate whether the presentation and analysis of the if-conditional that can be found in a range of language resources corresponds in fact to specialised discourse use. To carry out this comparison, we have drawn on two types of resources: the theoretical literature on conditional constructions on the one hand, and on the other, a selection of teaching-oriented resources, widely used by both teachers and students, namely Toeic manuals, English for Science and Technology (EST) textbooks, and online grammar sites. Details of the teaching resources consulted can be found in the Appendix.

6 In the abundant literature on conditional constructions, many different typologies have been proposed by philosophers, linguists and grammarians, based on logical or truth 
implications (Lewis 1976), on the conceptual domains or worlds to which the content of the conditional refers (Sweetser 1990), or on semantic distinctions (Comrie 1986). The applicability of these typologies to specialised discourse use proved however to be in most cases problematic.

Classifications of conditional constructions revolving solely around issues of logic and truth are difficult to apply to naturally occurring text. Many uses of conditionals that are unambiguous for speakers in context do not necessarily obey the principles of formal logic, while conversely examples of correct conditional reasoning given in TruthFunctional theory, such as "If Paris is the capital of France, (then) two is an even number", are often intuitively unacceptable. As many commentators have noted, natural language also requires some sort of plausible relationship between the two clauses making up the conditional construction. Moreover, while formal logic may be applicable to the use of if-conditionals in mathematics for example, it is largely inappropriate for medicine, an inductive rather than a deductive science, based on observation rather than on abstract logical reasoning.

8 The influential typology proposed by Eve Sweetser (1990) specifically addresses the nature of the relationship between the two parts of the conditional construction. Sweetser distinguishes conditionals in 'content', 'epistemic' and 'speech act' domains. In the content domain conditional, the relationship between two states of affairs takes place in a socio-physical world and is essentially causal (If Mary goes, John will go). ${ }^{1}$ In the epistemic domain the construction links premises and conclusions in a world of reasoning (if she's divorced, (then) she's been married). In the speech act domain, the ifclause justifies or explains the relevance of the speech act performed in the main clause (if I may say so, that's a crazy idea). This typology proved unhelpful for our purposes however. Whilst her content domain category is arguably too encompassing, the other two categories are of limited relevance for our corpus. We found practically no occurrences of the epistemic domain conditionals, the ones closest in usage to the formal logical if-then structure. As for speech-act conditionals, which are relevant primarily to conversation, they are unsurprisingly absent from our monologic data.

Other more functionally based classifications such as that of Anthanasiadou and Dirven (1997) also proved difficult to apply to our medical corpus. A major drawback with this as with many existing classifications is that they are mainly based on decontextualised examples, and are as a result under-specified for disciplinary discourses. The if operator is particularly polysemous and context-sensitive, as is also the case for French si (Adam 2005; Achard-Bayle 2005) and a fully contextualised approach is in our view essential. Moreover, few analysts tackling if-conditionals seem to have considered the question of genre. ${ }^{2}$ Given the now widely-recognised impact of genre on the syntactic strategies adopted by writers and speakers, and the importance of genre awareness in achieving mastery of disciplinary discourse, this seemed an important parameter to consider.

When one turns to teaching-oriented resources, further drawbacks are encountered in the way the if-conditional is presented. As in some of the above-mentioned studies, the construction is generally illustrated by decontextualised examples, based moreover on a restricted set of over-simplified rules. The emphasis is invariably on verbal morphology and mainly limited to a presentation of the three so-called canonical conditionals: 1) present + future (If I have time tomorrow, I will call you); 3 2) past + 'conditional' (If I knew how to drive, I would buy a car); 3) past perfect + 'conditional' perfect (If I had been free, I would have gone with you to the movies), with the occasional addition of the '0' sequence of if 
present + present (If it rains, plants grow). In four out of the seven EST manuals analysed here, for example, the only tense sequences mentioned are the three canonical forms, presented very prescriptively as being all that the student needs to know about this construction: "The conditional form is relatively straightforward so long as the student remembers the sequence of tenses that must be observed" (CW Unit 14; our emphasis). The if present + present sequence is found only in the three OUP textbooks (ELEC, IT, TT), where it is presented as interchangeable with conditional 1 and used to express general rules of the type "If current is passed through a solenoid, a magnetic field is set up" (ELEC).

11 The Toeic manuals likewise focus almost exclusively on the three canonicals, as the MCQ format of the Toeic test inherently excludes any 'freer' tense combinations. The present +present and past+past ('real in the past') conditionals are each mentioned only once in the four books. On the websites, one finds again a very marked skewing towards the canonical sequences: among the ten sections of Edufind, for example, only one is devoted to the zero conditional, and another to two types of 'mixed conditionals'. On the Eleaston site, which when consulted (March 2008) contained 51 exercises on if-conditionals, only two focus on 'mixed conditionals', one on 'past real' conditionals, and a small number contain examples of the ' 0 ' conditional, again used to express natural laws and generalisations. While there are passing remarks about the possibility of replacing will/ would with other modals depending on the degree of certainty of the outcome, the closed answer format of almost all the quizzes means that formal variants are generally ignored. Several of the teaching resources, however, devote space to the rather literary variants with should/were/had auxiliary inversion (Should the problem arise...) or the past subjunctive were (If I were you...), which do not occur at all in our specialised data.

12 None of these resources provides any information about the frequency of if-conditionals in general, nor are any possible differences in the relative frequency of the various canonical forms mentioned, though the absence of type 3 in TT, IT and ELEC can perhaps be taken as an implicit indication that this form is less frequent than the others in scientific and technical English.

13 Concerning clause ordering, the initial position of the if-clause is usually presented implicitly as the default option in all these teaching resources. Almost all the examples and exercises in the EST and Toeic manuals have initial if-clauses (or P-clauses), ${ }^{4}$ and when initial Q-clauses do occur, no explanation is given for this alternative order. The only remark made concerns a purely formal feature, punctuation:

If we start a conditional sentence with an 'if' clause, we use a comma before the main clause. However, when we start a conditional sentence with the main clause, there is no need to include a comma. (Target Score: 135)

14 On the Edufind and Eleaston websites, where initial if-clauses also largely dominate (75\% and $68 \%$ respectively), clause ordering often seems determined simply by considerations of screen layout: when the construction is presented as a table or matching exercise, the main or subordinate clause is systematically positioned on the same half of the screen. On the rare occasions when clause order is mentioned in the accompanying explanations, it is presented as an entirely random feature: "The order of the two clauses does not matter" (Eleaston).

15 The explanations given in these teaching resources about the functions of if-conditionals vary considerably in their terminology, but, as with formal features, they focus on a restricted range. In the three OUP EST textbooks, the main function of the construction is 
that of expressing the core scientific action-and-effect relation (either real with canonicals 0 and 1, or imagined with sequence 2), while in the three EST textbooks produced specifically for French students (EAST, CW and TS), the semantics of the construction are explicitly linked to the three canonicals and expressed as varying degrees of hypothesis. In the Toeic manuals, one finds the same explicit link between a particular form and a specific meaning, though the terms generally used are real/unreal (present or past). The terminology used on the websites is highly varied, not to say confusing, based either on the canonical labels (Type 2, or Second Conditional), semantics (Unreal Past Conditionals), or even - misleadingly - on truth values (True/Untrue Conditionals). Overall, it seems apparent that these resources pay scant attention to the actual discourse functions of conditional constructions and to their role in building up an argument.

\section{Study data}

16 The data used for this study come from two genres of medical discourse, research articles (RAs) and conference presentations (CPs), both within the field of oncology. Table 1 gives an overview of the data.

Table 1. Data sample

\begin{tabular}{|c|c|c|c|c|}
\hline Genre & $\begin{array}{c}\# \\
\text { texts }\end{array}$ & \# words & \# occ. & $\begin{array}{c}\text { Ratio } \\
\text { if } / 1000 \mathrm{w} .\end{array}$ \\
\hline $\begin{array}{l}\text { Research Articles (RA) } \\
\text { of which: NSE } \\
\\
\text { FSE }\end{array}$ & $\begin{array}{l}60 \\
30 \\
30\end{array}$ & $\begin{array}{l}226,298 \\
111,907 \\
114,391\end{array}$ & $\begin{array}{c}217 \\
119 \\
98\end{array}$ & $\begin{array}{l}0.96 \\
1.06 \\
0.85\end{array}$ \\
\hline $\begin{array}{l}\text { Conference Presentations (CP) } \\
\text { of which: NSE } \\
\\
\text { FSE }\end{array}$ & $\begin{array}{l}30 \\
15 \\
15\end{array}$ & $\begin{array}{l}72,106 \\
39,454 \\
32,652\end{array}$ & $\begin{array}{l}216 \\
152 \\
64\end{array}$ & $\begin{array}{c}3 \\
3.85 \\
1.96\end{array}$ \\
\hline Total & 90 & 298,404 & 433 & 1.45 \\
\hline
\end{tabular}

17 The sources for the written texts are: Journal of Clinical Oncology (2003), International Journal of Radiation Oncology (2003), and The Lancet Oncology (2003-2004). The conference presentations were delivered at the First Annual European-American Conference on Gastrointestinal Oncology: Cancers of the Lower Gastrointestinal Tract, 22-24 Sept. 1994, Bordeaux, France.

The research articles subset comprises 60 articles from two leading international journals; all follow the IMRD ${ }^{5}$ format and can be considered to be standard data-based medical RAs. Two author groups are equally represented, with 30 articles by native English-speaking authors (RA-NSE) and 30 by French-speaking authors writing in English (RA-FSE). We made this distinction so as to compare any potential areas of difference in argumentative strategies between the two groups, with a view to developing postgraduate teaching applications for NNS researchers in reading and writing research publications in English.

19 The second subset, a spoken research genre, comprises 30 research talks delivered at an international conference by the same two author groups, with 15 talks by native speakers (CP-NSE) and 15 by French speakers of English (CP-FSE), again with a view to developing oral/aural applications for NNS researchers. 
20 It should be emphasised that in our search for conditional occurrences, we were only interested in if, the prototypical operator of conditionality in English, and have excluded other conditional subordinators (on condition that, provided that, unless, etc.). We have also excluded occurrences where the subordinate clause is a subject or object clause (and where if is the equivalent of whether), as well as occurrences of as if. However, the study covers both the full if $P, Q$ construction and elliptical $P$-clauses (such as if necessary), as the latter were relatively common in the data. Having made these adjustments this left us with a total of 433 occurrences: 217 in the RAs, and 216 in the CP subset, for an overall corpus size of just under three hundred thousand words.

\section{Methodology}

Giv en the emphasis on the verb sequences in the literature on conditionals, a first essential step was the examination of the verb forms. It was important not only to see to what extent the traditional EFL paradigm based on the three specific canonical tense sequences was reproduced in our medical data, but also to examine any major differences in the verb sequences preferred in the data-sets. A second formal feature focused on was that of clause order within the conditional sentences. As the initial positioning of Pclauses is usually presented as a norm, we were interested in seeing whether any preferential ordering could be discerned in our medical data, and, if so, whether motivated explanations could be proposed that could act as guidelines for text producers. All the occurrences were classified according to three possible positions of the P clause: initial, medial, or final.

Initial: If you add leucovorin the toxicities are really similar (CP)

Medial: This tumor is very amenable if it's a carcinoma by biopsy to local excision (CP)

Final: Patients were eligible for participation if they were 18 years of age or older (RA)

22 A final formal feature examined in the RA subset was that of the location of the conditional construction within the IMRD sections. It is well-known that there is a strong correlation between the frequency of certain linguistic features and the section of the text (Hyland 1998; Adams-Smith 1984). We wished to see whether this was also the case with conditionals.

This formal classification was then completed by an analysis of the functions fulfilled by the conditional constructions in their discourse contexts. We had no predefined analytical categories in mind and instead concentrated on identifying the dominant rhetorical functions in relation to the regularities in the data. Three main functions emerged from this process: Factual, Refocusing, and Discourse Management functions each subsequently divided into a number of sub-categories.

The Factuals category broadly corresponds to what have often been called course of event, generic or habitual conditionals in other functional approaches (Athanasiadou \& Dirven 1997; Ferguson 2001) and to the category of real conditions (present or past) often referred to in pedagogical grammars and manuals. However, the term 'Factual' seems particularly relevant to scientific discourse, where the facticity (Latour 1987), or status as fact, of its statements about the natural world is established by observing regularities and correlations, and by carefully defining the conditions under which the facts hold. In clinical medicine, an observational rather than a theoretical science, facticity is 
important in order to enable protocols and findings to be compared and reproduced. A substitution test of if by when (if [when] X, Y) was used in order to confirm allocation to this category, with the if-operator specifying the exact conditions under which the medical decisions and procedures were carried out, as in example (1):

(1) The dose of paclitaxel was reduced by $20 \%$ if the patient had Grade 4 neutropenia that lasted $>5$ days (RA-NSE) instruct or guide readers and listeners in following the development of the text or talk. Ifconditionals can be used to introduce new topics (5) or to instruct readers on where to direct their attention (6):

(5) Now if we go to patients who experienced mucositis toxicity...(CP-NSE)

(6) If you look at the crossover versus the non-crossover group, there was a doubling of survival (CP-NSE)

\section{Results}

\subsection{Frequency}

27 As can be seen from Table 1 above, the frequency of if-conditionals varies considerably with genre, ranging from only $0.96 / 1000 \mathrm{w}$. in the RA to 3 times as many in the CPs (3/1000w.). This corroborates other studies which have found the construction to be more frequent in speech than in writing, both in general and in specialised discourses (Ford \& Thompson 1986; Biber et al. 1999; Ferguson 2001). While the difference between the two speaker groups is negligible in the RA (NSE 1.06 vs. FSE $0.85 / 1000 \mathrm{w}$ ), it is considerably more marked in the $\mathrm{CP}$, where the native English speakers use the construction twice as frequently as their French-speaking colleagues (NSE 3.85 vs. FSE 1.96), a point we return to later in section 5.4. 


\subsection{Forms}

\subsubsection{Verb sequences in the RA}

The medical RA subset presents a very specific profile of use. The verb sequences used are firstly starkly different from those encountered in the literature on conditionals. The three traditional canonical verb sequences are extremely rare, representing under $5 \%$ of the total occurrences in both the NSE and FSE articles (see Table 2 below). It is clear that any novice or NNS author, who has been led to believe that such forms are the norm, will therefore be ill-prepared for this reality of discourse practice.

\section{Table 2. Canonical verb sequences in the RA}

\begin{tabular}{|l|c|c|c|}
\hline \multicolumn{1}{|c|}{ Verb sequence } & NSE & FSE & All RAS \\
\hline Canonical 1 & 2 & 0 & 2 \\
\hline Canonical 2 & 4 & 3 & 7 \\
\hline Canonical 3 & 1 & 0 & 1 \\
\hline All canonical forms (1,2,3) & 7 & 3 & $10(4.6 \%)$ \\
\hline Other combinations & 112 & 95 & 207 \\
& & & $(95.4 \%)$ \\
\hline
\end{tabular}

Our RA subset reveals instead a variety of other verb sequences. The most frequent of these are given in Table 3:

Table 3. Other Verb Sequences in the RA

\begin{tabular}{|l|c|c|c|}
\hline \multicolumn{1}{|c|}{ Verb sequence } & NSE & FSE & All RAs \\
\hline Present + present & 9 & 12 & 21 \\
\hline Present + modal & 9 & 15 & 24 \\
\hline Present + past & 2 & 4 & 6 \\
\hline Modal + other & 5 & 2 & 7 \\
& & & \\
\hline Past + past & & $44(44.9 \%)$ & 105 \\
& 4 & 1 & $(48.4 \%)$ \\
\hline Past + modal & 4 & 2 & 5 \\
\hline Past perfect + past & $17(14.2 \%)$ & $8(8.1 \%)$ & $25(11.5 \%)$ \\
\hline Truncated verb sequences & 1 & 7 & 8 \\
\hline Other sequences & 112 & 95 & 207 \\
\hline All non-canonical forms & & & \\
\hline
\end{tabular}

These 'non-canonical' forms represent overall $95 \%$ of the if-conditionals in the data. A minor fraction of these combinations, amongst those classified as 'other sequences ' in Table 3, are decidedly odd. In (7), for example, the use of the modal might in both the P and $Q$ clauses can almost certainly be attributed to a lack of linguistic expertise by the FSE author(s):

(7) if TGF-b overexpression might be required for the initial expansion, the maintenance of the fibrotic lesion might be independent of TGF-b action. (RA-FSE)

However, the great majority of the non-canonical combinations are appropriate in context and occur with far greater regularity than those in any of the canonical sequences. The most frequent combination in both the FSE and NSE articles, representing globally $48.4 \%$ of occurrences, is that of two past tenses: 
(8) Patients were eligible if there was evidence of spread of tumor to regional lymph nodes (Dukes' C or tumor, lymph node, metastasis stage III tumor). (RA NSE) worth pointing out. This construction is widely-taught, but appears in fact to be irrelevant to the argumentative needs of the specialised discourse studied here, as the researchers would be doing themselves a disservice if they opened up past hypothetical spaces in which a different set of results might have been obtained. Alternatives likely to cast serious doubt on their claims are therefore not raised, obviating the need for canonical 3 .

Table 4. Canonical verb sequences in the $\mathrm{CP}$

\begin{tabular}{|l|c|c|c|}
\hline \multicolumn{1}{|c|}{ Verb sequence } & NSE & FSE & All CPS \\
\hline Canonical 1 & 13 & 5 & 18 \\
\hline Canonical 2 & 8 & 1 & 9 \\
\hline Canonical 3 & 0 & 0 & 0 \\
\hline All canonical forms $(1,2,3)$ & 21 & 6 & $27(12.5 \%)$ \\
\hline Other combinations & $131(86.2 \%)$ & $58(90.6 \%)$ & $189(87.5 \%)$ \\
\hline
\end{tabular}

The wide variety of other verb sequences, accounting for $87.5 \%$ of all occurrences, is shown in Table 5 . In strong contrast to the RA, however, where the past + past pattern was the most frequent, it is the present + present pattern which predominates in the CP (31.5\% of all occurrences). The function generally attributed to this pattern in EST 
manuals is that of stating general scientific laws or timeless truths; in the medical CPs studied here, however, it is used, like canonical 1, to describe regular clinical practice, the presentation of personal experience and know-how being a typical feature of the genre:

(11) if tumor is left then we do a postoperative radiotherapy (CP-FSE)

The second largest sequence, present + modal (21.7\%) also refers primarily to clinical practice but statements are hedged, reflecting the inherently probabilistic basis of medical knowledge:

(12) if the patient is absolutely inoperable you can try to treat some very superficial T2NO (CP-FSE)

These two sequences combined account for over half the occurrences. The very high proportion of patterns in the present is probably due to the real-time delivery of the talk, in that speakers prefer the immediacy of the present tense to the distance created by the past, and also to the need to refer constantly to the visuals projected on the screen during the talk.

40 Two other patterns characteristic of the $\mathrm{CP}$, although seldom pointed out to learners, are the Q-less P-clause and the present + past pattern. The Q-less P-clause, used for slide requests (If I could have the next slide please?), although syntactically incomplete is not pragmatically incomplete in this context, and suffices, as Ford points out, to make a polite request: " $A$ 'main' clause seems to be unnecessary [...], with the if-clause alone becoming a conventional format for proposing another's action." (1997: 405).

41 The present + past sequence is used in the CP with the specific role of semiotic management:

(13) now if we look at just some factors, the disease-free survival was less (CP-NSE)

This sequence enables the speaker to manage a smooth transition between the current enunciative space of the talk (the polite invitation in the present tense to look at the slide), to the research or content space of the results obtained in the past (disease-free survival was less...).

Table 5. Other verb sequences in the $\mathrm{CP}$

\begin{tabular}{|l|c|c|c|}
\hline \multicolumn{1}{|c|}{ Verb sequence } & NSE & FSE & All CPs \\
\hline Present + present & 45 & 24 & 69 \\
\hline Present + modal & 29 & 18 & 47 \\
\hline Present + past & 13 & 0 & 13 \\
\hline Modal + other & 11 & 2 & 13 \\
\hline Past + past & 6 & 0 & 6 \\
\hline Past + modal & 4 & 0 & 4 \\
\hline Q-less P-clause & 13 & 2 & 15 \\
\hline Truncated verb sequences & 6 & 7 & 13 \\
\hline Other sequences & 4 & 5 & 8 \\
\hline All non-canonical forms & $131(86 \%)$ & $58(90.6 \%)$ & $189(87.5 \%)$ \\
\hline
\end{tabular}




\subsubsection{Clause ordering}

The initial positioning of if-clauses can only be considered to be the norm in the CPs. In the RAs, on the other hand, final P clauses are more frequent than initial P clauses.

Table 6. Clause ordering in the RA and CP

\begin{tabular}{|c|c|c|c|c|}
\hline Genre & \# Occ. & \multicolumn{3}{|c|}{ Positioning (\%) } \\
\hline & & Initial & Medial & Final \\
\hline RA & 217 & 43.3 & 3.2 & 53.4 \\
NSE & 119 & 41 & 3.3 & 55 \\
FSE & 98 & 45 & 3 & 52 \\
\hline CP & 216 & 75.5 & 11.1 & 12.6 \\
NSE & 152 & 75.8 & 11.1 & 13.1 \\
FSE & 64 & 76.5 & 10.9 & 12.5 \\
\hline
\end{tabular}

The tendency towards the final positioning of $\mathrm{P}$ clauses is contrary to what is normally presented in the literature as the default positioning but would appear to be a pronounced specificity of the medical RA and characteristic of both author groups (NSE $55 \%$, FSE 52\%). Several factors can be seen to motivate this choice. A large proportion of these postposed $\mathrm{P}$ clauses in both author groups involve 'factual' type conditionals relating to methodology and treatment decisions taken:

(14) Fine needle aspiration was performed if involvement of inguinal nodes was clinically suspected. (RA-FSE: Meth.)

(15) Patients were eligible for participation if they were 18 years of age or older (RA-NSE: Meth.)

In examples such as (14) or (15) the various defining and criterial uses of P clauses often seem better suited both cognitively and discursively to final positioning. The particular research decisions taken are presented before the precise operational definitions and/or explanations relevant to these decisions. Positioning of the if-clause can also be exploited on occasion for rhetorical effect:

(16) Associations between obliteration rate (OR) and parameters included in the univariate analysis were studied using the chi-square test where variables could be reduced to classes if the counts were $>5$. If the minimal count was $<3$, a nonparametric Mann-Whitney test was used. (RA-FSE: Meth.)

By alternating the Q-P, P-Q order in these two consecutive sentences, the RA author is thus able to highlight the contrasting methods used in the case of counts $>5$ and $<3$. It appears therefore that the emphasis in conditional theory on initial positioning of ifclauses is not only rather misleading but also masks this possible discursive function of the construction. ${ }^{6}$

In marked contrast to the RA, three-quarters of if-clauses in the $\mathrm{CP}$ are initial. Although initial positioning is often presented as a global norm across speech and writing (cf. section 2 supra), it seems more accurate to say that the question of mode plays a predominant role. In real-time processing it is important for speakers to first provide the background for the assertion in Q, by specifying under which conditions it holds, in order to avoid misinterpretation and back-processing by listeners. They also need to focus the listener's attention on the referents needed in the subsequent discourse. This 
'presentational' function of initial if-clauses comes across clearly in many occurrences in the data:

(17) If we look at the toxicities used in some slides before we see that with this schedule we can have less toxicity than with the others (CP-FSE) considerably in the preferred functions that if-conditionals fulfil (see Table 7).

Table 7. Functions in the RA and CP

\begin{tabular}{|c|c|c|c|}
\hline & Factuals \% & Refocusing \% & Discourse \% \\
\hline All RAs & $\mathbf{6 1}$ & $\mathbf{3 8}$ & $\mathbf{1}$ \\
NSE & 68 & 32 & 0 \\
FSE & 53 & 46 & 1 \\
\hline All CPs & $\mathbf{4 1}$ & $\mathbf{3 3}$ & $\mathbf{2 6}$ \\
NSE & 41.5 & 28 & $30.5(47$ occ.) \\
FSE & 41 & 45 & $14(9$ occ. $)$ \\
\hline
\end{tabular}

\subsubsection{Functions in the RA}

The medical RA also presents a very specific profile functionally speaking. What are usually presented as the prototypical hypothetical or predictive functions of ifconditionals are in fact far from 'typical' in the medical research article. What predominates instead is a particular type of Factual conditional.

The practical absence of Discourse Management conditionals in the RA should not come as a surprise. All the medical RAs follow the standardised IMRD format, and there is thus no need for any extra meta-discursive signals to guide the reader through the text. The Refocusing type of conditional functions, enabling researchers to make use of the argumentative potential of the construction account for $38 \%$ of occurrences. Within this category however, any predictions and hypotheses that do occur are frequently hedged, as envisaging hypothetical alternatives or engaging in speculation is contrary to one of the main objectives of research discourse, namely that of establishing facts. 
(19) Also, if preoperative therapy is administered at the time of diagnosis it might be more effective because the metastatic burden may be the smallest at this point. (RA-NSE: Disc.) establish facticity in scientific texts. While it is true that reference to Factual conditions in scientific texts is usually addressed in EST manuals (cf. section 2), reference is invariably only made to factual conditions in the present, expressing some type of generalisation or timeless truth. In our medical RAs, the great majority of factual ifconditionals involve the past + past pattern and refer to specific pieces of research accomplished by the author and colleagues, rather than to the statement of any general truths.

(20) If $10 \%$ or more of the malignant nuclei were stained, the slide was scored as negative (RA-NSE: Meth.)

\subsubsection{Functions in the $\mathrm{CP}$}

Management. Whereas we found only one occurrence in the 60 RAs, there are 56 in the 30 CPs (i.e. $>100$ times as many). Two factors can be adduced to explain this difference. Firstly, the structure of conference presentations is more variable from one speaker to another than that of the RA. The absence of a template therefore makes it necessary for speakers to guide their audience through the talk by signalling its organisation. Moreover, as various analysts of lengthy expository monologues have pointed out, organizational markers are necessary in this type of discourse in order to chunk the continual verbal flow into manageable segments and mark topic boundaries (Rilling 1996; Thompson 2003). If-conditionals are one of the preferred means to do this; in Rilling's study of university lectures, for example, of the nine most frequent 4-word topic shifters, four are if-conditionals. A typical example from our data is:

(21) If we now go on to discuss the other problem, that is the local recurrence problem, this is a serious problem (CP-NSE)

Another reason for the large number of discourse management if-conditionals is linked to the fact that scientific speakers' need to manage concurrently two kinds of semiotic spaces - the verbal space, or spoken commentary, and the visual space, or what is projected onto the screen. As the latter is an integral part of the scientific content, the two spaces need to be connected by intratextual references for the discourse to be cohesive (Young 1990: 91). If-conditionals have the advantage of giving a suitably polite directive to the audience, not threatening to the listener's negative face.

(22) If you look at the number of patients that were treated, ... (CP-NSE) 

in the teaching literature on conditionals. ${ }^{7}$

\subsection{NSE / FSE differences}

As several of the tables shown above indicate, in addition to the differences between genres, there are also some interesting divergences in the way the two speaker groups use if-conditionals in specialised discourse. This section discusses the most significant differences observed.

\subsubsection{NSE / FSE differences in the RA}

61 In the RA, there are overall few notable differences concerning the forms of ifconditionals in the two author groups. In both sets of articles final positioning of $\mathrm{P}$ clauses is preferred and recourse to the three canonical conditionals is very rare (see Tables $2 \& 6$ ). Both groups instead frequently use the combination of two past tenses in order to describe real situations in the past. In the FSE subset there are however slightly more verb sequences involving two present tenses or the present + modal sequence than in the NSE subset. This discrepancy can be related to the slightly higher proportion of refocusing type conditionals in the FSE subgroups.

62 As Table 7 illustrates, although discourse management functions are conspicuously absent in both author groups, there are some differences with regard to the distribution of the refocusing and factual functions. Factuals, even if predominant in both author groups, are more widely used by the NSE authors than by their FSE counterparts. Refocusing conditionals, on the other hand, are more exploited by the FSE authors than by the NSE authors ( $46 \%$ and $32 \%$ respectively), particularly with the contrastive and concessive uses, where one invariably finds two present tenses:

(23) If the results are encouraging for $\mathrm{T} 2$ lesions, the rate of local failure with RT [radiotherapy] ... for T3 lesions remains $>20 \%$. (RA-FSE: Disc.)

(24) Even if these local failures are surgically salvageable in most patients, they are certainly not trivial events and, in some cases, may have a deleterious impact on survival. (RA-FSE)

63 These differences can be related not only to a certain amount of language interference (French si has a wider range of values than English if) but also to the potential influence of different national academic writing styles. Lack of space prevents us from examining this issue here in detail but in a previous study contrasting the use of French si and English if in the medical research article (Carter-Thomas 2007), French authors were seen to make greater use of the refocusing and manœuvring capacity of the conditional operator $s i$ in argumentation and it is therefore possible that this trait is also carried over to their research writing in English.

64 The differences in the distribution of functions between the two author groups is also reflected in the distribution of if-conditionals across the RA IMRD sections. Although ifconditionals occur with a similar frequency in both author groups (see Figure 1) the occurrences are not distributed in the same way over the RA sections. 
Figure 1. Comparative distribution of if-conditionals by section in the NSE and FSE RAs

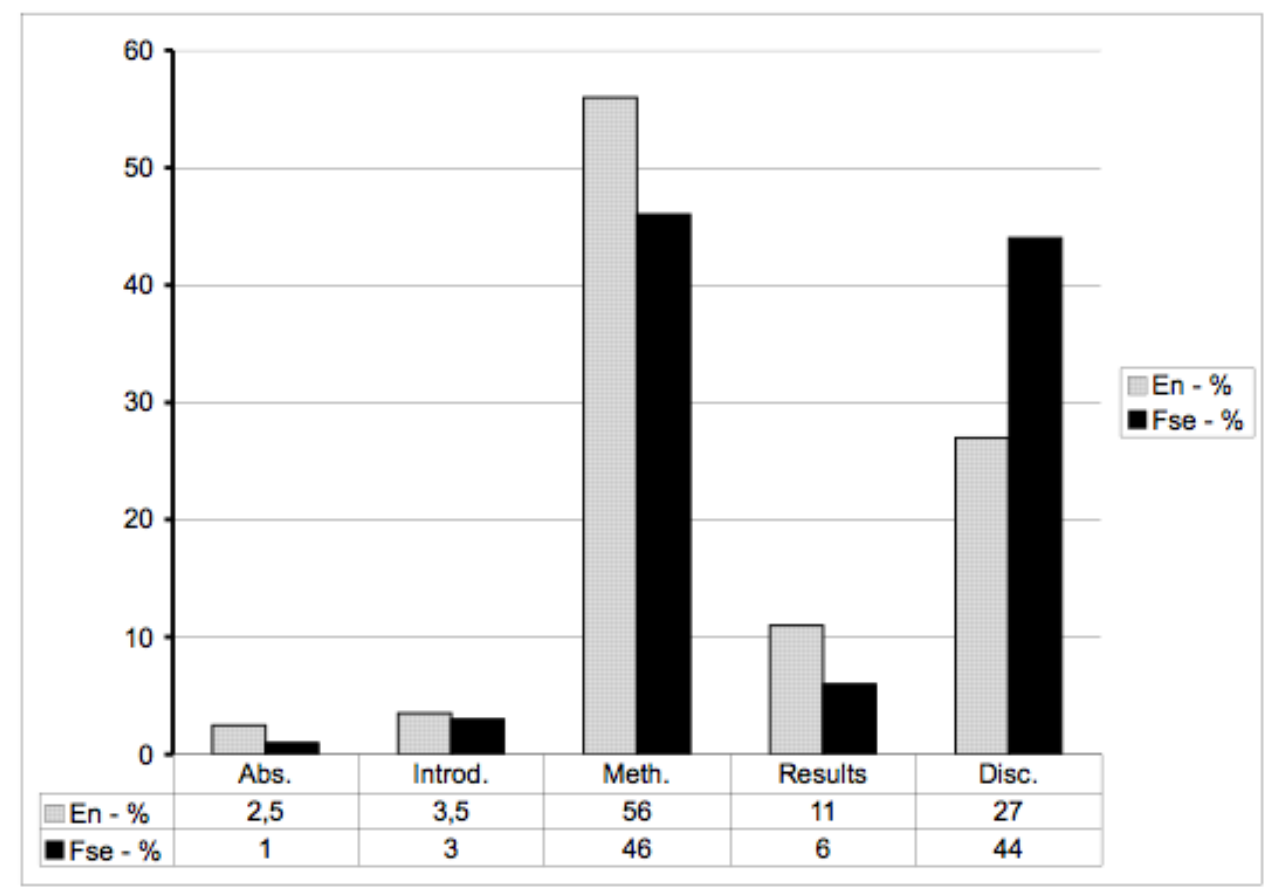

As is well-known there are considerable differences in communicative function from one section of the research article to another (Swales 1990; 2004). In particular a sharp distinction is maintained between the research data and its interpretation. In the NSE group the majority of occurrences are in the more descriptive Methods and Results sections (67\%), as opposed to only $27 \%$ of occurrences in the Discussion section. Those of the FSE authors also contain a substantial number of occurrences in the Methodology section (46\%), but they also contain an almost equally high percentage of occurrences in the more polemical Discussion sections (44\%), reflecting the greater recourse to refocusing functions of if-conditionals noted above and exploitation of the construction's argumentative potential.

\subsubsection{NSE / FSE differences in the CP}

66 The need for syntactic structures that are adapted to the specific communicative requirements of the conference presentation genre is not always fully apprehended by the FSE speakers, leading to much greater differences between the two speaker groups than those observed in the RA. This is to some extent understandable as in the $\mathrm{CP}$ no hard and fast rules, or even models that can be analysed and then imitated, exist.

67 A first major difference between the two speaker groups concerns the frequency with which they use if-conditionals in their talks: though overall if-conditionals are three times more frequent in the CP than in the RA, this is mainly due to the NSE speakers who use the construction twice as frequently as FSE authors do (NSE: 3.8/1000w. vs. FSE: $1.9 / 1000 \mathrm{w}$.). Or, to put it differently, the ratio of if-conditionals in the CP compared to the RA is 4:1 in the case of NSE, and only 2:1 for FSE. When switching from a written to an oral mode of presentation, the French speakers do not differentiate as radically as the American speakers do in their choice of preferred syntactic patterns. This confirms our 
earlier findings on other syntactic constructions such as the passive, extraposition, pseudo-clefts and inversion (Carter-Thomas \& Rowley-Jolivet 2001; Rowley-Jolivet \& Carter-Thomas 2005): in all cases, the constructions characteristic of written scientific discourse are more prevalent in FSE talks, while those characteristic of speech are much less in evidence.

There are also some notable differences with regard to the three main functions of ifconditionals in the two speaker subsets. Although Factual functions are exploited in the same proportion in both groups, the FSE researchers make greater use proportionally speaking of the Refocusing functions (NSE 28\%; FSE 45\%), reflecting the greater recourse to the argumentative capacity of refocusing if-conditionals noted previously among FSE RA writers. The most striking difference however is in the Discourse management function, that is, if-conditionals used to signal the structure of the talk and to direct the audience's attention, as in: Now if we look at some other series... It is heavily used by the NSE speakers ( 47 occ., representing $31 \%$ of all if-conditionals in their talks), but only sparsely by the FSE speakers (a mere nine occurrences; see Table 7). It would appear that this pragmatic use of the if-conditional is largely unfamiliar to the latter group, no doubt in part because it is granted so little attention in EFL manuals. Given its important discourse functions in the $\mathrm{CP}$, this raises the possibility that their talks may be less clearly signposted and with less attention paid to politeness strategies. EFL learners are generally taught logical link-words and set expressions - on the other hand, therefore, I will now move on to my second point, etc. - to structure their discourse. However, many if not most of these do not occur at all in our data, in either speaker group. Incorporating some explanations of the more pragmatic uses of conditionals, within a generally more genresensitive approach to English syntax, would prepare learners more completely for the reality of disciplinary discourse use they are likely to encounter.

\section{Conclusion}

This study of the frequencies, functions and forms of if-conditionals in two medical research genres has highlighted several interesting features of specialised discourse use. We have seen firstly that if-conditionals are overall much more frequent in the spoken than in the written genre. This tallies with the findings of several studies comparing ifconditionals in speech and writing in general, so on this point specialised discourse is not noticeably different.

Several of the formal features of the construction, however, diverge markedly from what the theoretical and pedagogical literature present as the norm. Whereas if-conditionals are invariably presented in the literature with the P-clause in initial position, this is by no means the case in the medical RA. On the contrary, initial positioning seems to be attributable to modal factors such as the constraints of cognitive processing in speech rather than being a characteristic feature of the construction itself. We have also noted that certain verb sequences in if-conditionals are highly genre-specific, with the RA being characterised by the past + past pattern and to a lesser extent truncated forms. In the CP, the present + present sequence dominates, while two additional patterns - present + past and the Q-less P-clause - appear motivated by the semiotic and pragmatic parameters of the genre. Most importantly for teaching applications, we have seen that the emphasis in EFL/EST manuals on the three 'canonical' verb patterns is largely irrelevant to the 
research discourses of medicine. In both the RA and the $\mathrm{CP}$, these patterns represent only a fraction of all verb forms used in the construction. ${ }^{8}$

71 It is clear that learners who have been led to believe that only these forms exist and that they can be used in all circumstances will be ill-equipped for either producing or processing medical research discourse. This discrepancy is undoubtedly linked to the incompatibility between the rhetorical aims of the medical research genres and the habitual semantics of the 'canonical' forms, namely prediction, supposition, and counterfactuality. The functions fulfilled by if-conditionals in our corpus appear on the contrary to be very genre-specific. Each of the two genres makes preferential use of a particular function: Factuals in the RA and Discourse Management in the CP. These preferences are rhetorically motivated, in that they correspond in each case to the communicative and argumentative needs of the genre in question.

At several points in this study, however, we have noted differences between the native English writers/speakers and their French counterparts. In the RA, the FSE group differs from the NSE by a rather different distribution of if-conditionals over the RA sections and greater use of the Refocusing function. While some of these differences can perhaps be attributed to interference from French or to different writing styles, others, we would contend, are linked to the way such common syntactic patterns as the if-conditionals are generally presented to learners. The much lower frequency of if-conditionals in the FSE CPs, for example, can probably be attributed to a lack of awareness of the pragmatic and discourse management functions of the construction.

Our study has brought to light some important discrepancies between the general theory and rather prescriptive rules found in learner manuals on if-conditionals on the one hand, and specialised discourse practice on the other. If teaching oriented resources give a misleading or incomplete picture, learners may be unfamiliar with certain verb patterns and functions, and therefore risk either misunderstanding certain usages or being less rhetorically effective themselves in the different genres they need to master. Teaching ifconditionals using decontextualised examples, or focusing on purely logical and abstract meanings, without taking into account the specific requirements of the genre and discipline, can even be counter-productive.

What is needed is a more genre sensitive approach to such common syntactic constructions as the if-conditional. This includes familiarising learners therefore with the specificities of the syntactic patterns they are likely to meet when reading, writing or speaking the discourse of their specialised communities. If a more genre-sensitive and discoursal approach to syntax is taken, learners will be more aware of the linguistic and discursive specificities of their discipline and its associated genres and therefore more adequately prepared to take part in the life of their discourse communities. 


\section{BIBLIOGRAPHY}

Achard Bayle, Guy. 2005. "Si polysémique et Si polyphonique". In L. Perrin (ed.) Le sens et ses voix. Dialogisme et polyphonie dans la langue et le discours. Collection Recherches linguistiques $\mathrm{n}^{\circ} 28$. Université de Metz, 407-434.

Adam, Jean-Michel. 2005. "Variété des usages de SI dans l'argumentation publicitaire”. In M. Burger et G. Martel (eds.). Argumentations et communications dans les médias. Québec: Nota Bene, 81-109.

Adams-Smith, D. E. 1984. "Medical discourse: Aspects of author's comment”. The ESP Journal 3, 25-36.

Athanasiadou, A. et R. Dirven. 1997. "Conditionality, hypotheticality, counterfactuality”. In A. Athanasiadou et R. Dirven (eds.). On Conditionals Again. Amsterdam: John Benjamins, 61-96.

Barber, C. L. 1962. "Some measurable characteristics of modern scientific prose". In F. Behre (ed). Contributions to English Syntax and Philology. Gothenburg: Almqvist and Wiksell, 21-43.

Biber, D., S. Johansson, G. Leech, S. Conrad, et E. Finegan. 1999. Longman Grammar of Spoken and Written English. Harlow, GB: Pearson Education.

Carter-Thomas, S. 2007. "The 'iffiness' of medical research articles. A comparison of English if and French si". In K. Flottum (ed.). Language and Discipline Perspectives on Academic Discourse. Newcastle, GB: Cambridge Scholars Press, 161-188.

Carter-Thomas, S. et E. Rowley-Jolivet. 2001. "Syntactic differences in oral and written scientific discourse: the role of information structure”. ASp 31-33, 19-37.

Collins COBUILD English Grammar. 2005. Collins Cobuild.

Comrie, B. 1986. “Conditionals: A Typology”. In E.C. Traugott, A. ter Meulen, J.S. Reilly, et C.A. Ferguson (eds.). On Conditionals. Cambridge: Cambridge University Press, 77-99.

Dancygier, B. 1998. Conditionals and prediction. Cambridge: Cambridge University Press.

Facchinetti, R. 2001. “Conditional constructions in modern English legal texts”. In M. Gotti, et M. Dossena (eds.). Modality in Specialised Texts. Bern: Peter Lang, 133-150.

Ferguson, G. 2001. "If you pop over there: a corpus-based study of conditionals in medical discourse". English for Specific Purposes 20/1, 61-82.

Ford, C.E. 1997. "Speaking Conditionally: Some Contexts for If-clauses in Conversation". In A. Athanasiadou, et R. Dirven (eds.). On Conditionals Again. Amsterdam: John Benjamins, 387-413.

Ford, C.E. et S.A. Thompson. 1986. "Conditionals in discourse: A text-based study from English". In E. Traugott, A. ter Meulen, J.S. Reilly, et C.A. Ferguson (eds.). On Conditionals. Cambridge: Cambridge University Press, 353-372.

Hunston, S. 2000. Pattern Grammar. A corpus-driven approach to the lexical grammar of English. Amsterdam: John Benjamins.

Hyland, K. 1998. Hedging in Scientific Research Articles. Amsterdam: John Benjamins.

Latour, B. 1987. Science in Action. Cambridge, MA: Harvard University Press. 
Lewis, D. 1976. "Probabilities of conditionals and conditional probabilities". Philosophical Review 85, 297-315.

Prince, E.F., J. Frader, et C. Bosk. 1982. “On hedging in physician-physician discourse”. In R. J. di Pietro (ed.). Linguistics and the professions. Hillsdale NJ: Ablex, 83-97.

Rilling, S. 1996. "Lexical phrases as organisational markers in academic lectures: A corpus- and computer-based approach to research and teaching”. The ORTESOL Journal 17, $19-40$.

Rowley-Jolivet, E. 2007. “A genre study of if in medical discourse”. In K. Flottum (ed.), Language and Discipline Perspectives on Academic Discourse. Newcastle, GB: Cambridge Scholars Press, 189-214.

Rowley-Jolivet, E. et S. Carter-Thomas. 2005. “Genre awareness and rhetorical appropriacy: manipulation of information structure by NS and NNS scientists in the international conference setting". English for Specific Purposes 24, 41-64.

Salager-Meyer, F. 1994. "Hedges and textual communicative function in medical English written discourse". English for Specific Purposes 13, 149-170.

Swales, J. 1990. Genre Analysis. Cambridge: Cambridge University Press.

Swales, J. 2004. Research Genres. Cambridge: Cambridge University Press.

Sweetser, E. 1990. From Etymology to Pragmatics. Cambridge: Cambridge University Press.

Thompson, S. E. 2003. "Text-structuring metadiscourse, intonation and the signalling of organisation in academic lectures." Journal of English for Academic Purposes 2, 5-20.

Young, L. 1990. Language as Behaviour, Language as Code. Amsterdam: John Benjamins.

\section{APPENDIXES}

\section{Corpus of teaching resources on the if-conditional}

\subsection{Sample of 7 EST textbooks}

\begin{tabular}{|l|l|l|l|l|l|}
\hline Ref & Title & Authors & Publisher & Date & Level \\
\hline TEI & $\begin{array}{l}\text { Technical English for } \\
\text { Industry }\end{array}$ & $\begin{array}{l}\text { C St. J. Yates \& } \\
\text { A Fitzpatrick }\end{array}$ & Longman & 1988 & Intermediate \\
\hline CW & $\begin{array}{l}\text { English for the } \\
\text { Computer World }\end{array}$ & $\begin{array}{l}\text { M. Brookes } \\
\text { F. Lagoutte }\end{array}$ & Belin & 1993 & Intermediate \\
\hline ELEC & $\begin{array}{l}\text { Oxford English for } \\
\text { Electronics }\end{array}$ & $\begin{array}{l}\text { Eric H. Glendinning \& } \\
\text { John McEwan }\end{array}$ & OUP & 1993 & Intermediate \\
\hline EAST & $\begin{array}{l}\text { Écrire l'anglais } \\
\text { scientifique et technique }\end{array}$ & $\begin{array}{l}\text { Sally Bosworth-Gerome } \\
\text { Robert Marret }\end{array}$ & Ellipses & 1994 & Upper Intermediate \\
\hline IT & $\begin{array}{l}\text { Oxford English for } \\
\text { Information Technology }\end{array}$ & $\begin{array}{l}\text { Eric H. Glendinning \& } \\
\text { John McEwan }\end{array}$ & OUP & 2002 & $\begin{array}{l}\text { Intermediate } \\
\text { upper-intermediate }\end{array}$ \\
\hline TT & Techtalk to & Vicki Hollett & OUP & 2005 & Pre-Intermediate \\
\hline
\end{tabular}




\begin{tabular}{|l|l|l|l|l|l|}
\hline TS & Ticket for Science & $\begin{array}{l}\text { Frédérique Corbière- } \\
\text { Lévy }\end{array}$ & Hachette & 2006 & Intermediate \\
\hline
\end{tabular}

\subsection{TOEIC manuals}

\begin{tabular}{|l|l|l|l|}
\hline Title & Authors & Publisher & Date \\
\hline $\begin{array}{l}\text { Longman Preparation Series for the Toeic Test: } \\
\text { Advanced Course }\end{array}$ & Lin Lougheed & Longman & 2007 \\
\hline $\begin{array}{l}\text { Longman Preparation Series for the Toeic Test: } \\
\text { Introductory Course }\end{array}$ & Lin Lougheed & Longman & 2004 \\
\hline Target Score & Talcott \& Tullis & $\begin{array}{l}\text { Cambridge University } \\
\text { Press }\end{array}$ & 2006 \\
\hline Oxford Preparation Course for the ToeicTest & $\begin{array}{l}\text { (collective } \\
\text { authorship) }\end{array}$ & $\begin{array}{l}\text { Oxford University } \\
\text { Press }\end{array}$ & 2002 \\
\hline
\end{tabular}

\subsection{Online grammar resources}

The following websites were consulted (March 2008)

$<$ http://eleaston.com>

Section Grammar $>$ Verbs $>$ Conditional

$<$ http://www.edufind.com>

Section verbs and verb tenses $>$ sub-sections on if-sentences and the conditional

\section{NOTES}

1. All examples in this paragraph are from Sweester 1990.

2. See however Ferguson (2001), Facchinetti (2001) and Rowley-Jolivet (2007) for recent analyses of if-conditionals conducted from a genre perspective.

3. All examples taken from<http://eleaston.com>.

4. In much of the theoretical literature on conditionals, the subordinate if-clause is termed the Pclause and the main clause the Q-clause.

5. Introduction, Method, Results, Discussion, the usual format of the research article.

6. The respective ordering of the $\mathrm{P}$ and $\mathrm{Q}$ clauses also fulfills a vital role in information structuring. The initial section of the sentence will usually be the site of what the enunciator intends to be interpreted as given or topical information (Carter-Thomas \& Rowley-Jolivet 2001). In a conditional construction, an initially occurring 'if' acts as a signal to the receiver to provisionally accept a set of circumstances denoted by the $P$ clause as backcloth to a new state of affairs expressed in the $\mathrm{Q}$ clause. Lack of space prevents us however from developing these aspects further here.

7. Among the teaching resources consulted, the only one to mention the 'politeness' function of if -clauses, with ellipsis of $Q$ and a passing allusion to the influence of the spoken mode, is IT: "We use the action part of if-sentences, especially in spoken English, to give instructions in a polite way. The effect part is assumed." (IT, 70) 
8. To assess whether this is a discipline-specific feature or more generally characteristic of research discourse, it would be interesting to compare the quasi-absence of canonical verb sequences in medicine with texts from another discipline such as law, in which if-conditionals are known to be common (Facchinetti 2001).

\section{ABSTRACTS}

The aim of the present study is to examine possible discrepancies between the presentation of a core syntactic construction, the if-conditional, in the theoretical literature and in teaching resources and the way this construction is used in the specialised research discourse of medicine. We focus on three types of differences: differences in the frequency with which the construction is used, differences in the functions it fulfils, and differences in formal features (verb sequences and clause positioning). Two genres are examined: research articles and conference presentations produced by two groups of researchers, native English speakers and non-native (French) authors and speakers. Our analysis reveals some marked divergences between specialised discourse use and what is traditionally presented as the norm. Moreover, the differences observed between the two speaker groups lead us to argue that a more genresensitive and discourse-based approach to syntax is necessary, in order to raise learners' awareness of the linguistic and discursive specificities of their discipline and its associated genres.

Notre objectif dans cette étude est d'examiner les disparités éventuelles entre la présentation des constructions conditionnelles avec if dans la littérature théorique et dans les outils pédagogiques, et l'utilisation de cette structure dans un discours spécialisé, celui de la recherche médicale. Trois types de disparités sont examinés: dans la fréquence d'utilisation de la construction, dans les fonctions remplies et dans les formes employées (formes verbales et ordre des propositions). Deux genres sont traités : les articles de recherche et les communications de congrès réalisés par deux groupes de chercheurs anglophones et non anglophones (français en l'occurrence). Notre analyse met en évidence un certain nombre de divergences très nettes entre la réalité de l'emploi d'un discours spécialisé et ce qui est présenté traditionnellement comme la norme. De plus, les différences constatées entre les deux groupes de chercheurs nous conduisent à défendre un enseignement de la syntaxe plus axé sur le genre et le discours, afin de sensibiliser les apprenants aux spécificités linguistiques et discursives de leur discipline et de ses genres associés.

\section{INDEX}

Mots-clés: article de recherche, communication de congrès, construction conditionnelle avec if, discours médical, norme grammaticale vs emploi de spécialité

Keywords: conference presentation, grammatical norm vs specialised usage, If-conditional, medical discourse, research article 


\section{AUTHORS}

\section{ELIZABETH ROWLEY-JOLIVET}

Elizabeth Rowley-Jolivet is a Senior Lecturer and a member of Laboratoire Ligérien de Linguistique. Her research deals with genre analysis, written and oral scientific discourse, multimodality and the epistemology of science. Elizabeth.Jolivet@univ-orleans.fr

\section{SHIRLEY CARTER-THOMAS}

Shirley Carter-Thomas is a Senior Lecturer in English Linguistics at TÉLÉCOM \& Management SudParis (formerly INT) and a member of the CNRS Laboratory LATTICE (UMR 8094). Her research interests span functional and text linguistics, the analysis of scientific discourse, information structure and the contrastive analysis of English and French syntax.

Shirley.Thomas@it-sudparis.eu 